\title{
THE INCIDENCE OF SURGICAL SITE INFECTION IN ACUTE NON PERFORATED APPENDICITIS Suraj Raj Bhattarai ${ }^{1,{ }^{*}}$, Kishor Kumar Tamrakar ${ }^{1}$ \\ ${ }^{1}$ Department of General surgery, Chitwan medical College, Chitwan, Nepal
}

Received: 9 May, 2019

Accepted: 12 June, 2019

Published: 15 June, 2019

Key words: Acute appendicitis; Antibiotics; Appendectomy; Wound infection.

*Correspondence to: Suraj Raj Bhattarai, Department of Surgery, Chitwan Medical College, Chitwan, Nepal. Email:drsrbhattarai@hotmail.com

DOI:https://doi.org/10.3126/jcmc.v9i2.24525

\section{Citation}

Bhattarai SR, Tamrakar KK. The incidence of surgical site infection in acute non perforated appendicitis. Journal of Chitwan Medical College. 2019; 9(28):11-14.

\section{Peer Reviewed}

\section{ABSTRACT}

Background: Appendectomy is the most commonly performed emergency surgical procedure and has significant morbidity of surgical site infection (SSIs). Regarding this, there are conflicting reports and dilemma on use of optimal duration of antibiotics. The aim of this study was to evaluate the incidence of SSIs after three doses of perioperative prophylactic antibiotics (single dose before surgery and two doses postoperatively) after appendectomy in acute non- perforated appendicitis (NPA).

Methods: This cross sectional study was conducted in the department of General surgery, Chitwan Medical College Teaching Hospital, from May 2018 to April 2019. All the cases received single dose of antibiotics (ceftriaxone and metronidazole) during the induction of anesthesia and two doses of the same antibiotics postoperatively within 24 hours. SSIs was assessed on 2 nd and followed up till 7th postoperative day. The data collected was analyzed using SPSS version 16.

Results: In the study of 100 patients, who received perioperative three doses of antibiotics, the overall frequency of SSIs on 2 nd and 3rd postoperative day were $2 \%(p=.840)$ and $6 \%(p=.539)$ respectively, which was statistically not significant. In follow up after 3rd postoperative day, there was no evidence of SSIs. Statistically there was no significant difference in the incidence and grade of SSIs between age group, sex and duration of operation.

Conclusions: A combined three doses of perioperative antibiotics was adequate for SSIs prevention in patients of any age group and sex with acute NPA after appendectomy in usual operative time.

\section{INTRODUCTION}

Acute appendicitis is the most common cause of acute surgical emergency and appendectomy is among the most frequently performed emergency operations. ${ }^{1}$ One of the stages of acute appendicitis is uncomplicated appendicitis i.e. a hyperemic suppurative appendicitis, which is the most prevalent stage in patients diagnosed with appendicitis. Suppurative appendicitis is a pathological definition in which appendix inflamed without gangrene. As a preventive measure for surgical site infections, sur- geons tend to prescribe prophylactic antibiotics. ${ }^{2}$

Appendectomy for non-perforated appendicitis (NPA), is a clean contaminated surgery. Several authors have proved the efficacy of pre-operative antibiotics in preventing postoperative infective complications. ${ }^{3}$ Therefore, as a standard protocol, all the patients undergoing appendectomy are given prophylactic antibiotics half to one hour before surgery. ${ }^{4}$

Post-operative antibiotic treatment modalities for 
NPA cases vary from center to center. Whether these are necessary or even required at all for reducing post-operative complications and SSIs in these cases has not been elaborated in detail in medical literature. The current practice in our hospital for NPA, the antibiotics are continued postoperatively two doses or till discharge of the patient. The current study was therefore carried out to determine the incidence of SSIs who received single dose of antibiotics before induction of anesthesia and same antibiotics two doses post-operatively within 24 hours (in total of 3 doses perioperatively) after appendectomy in NPA.

\section{METHODS}

This prospective study of 100 consecutive patients was conducted at the department of General surgery, Chitwan Medical College Teaching Hospital, from May 2018 to April 2019 after IRC approval. It included all the patients of acute NPA after appendectomy in all age group. The diagnosis was made after clinical evaluation, total leucocyte count, abdominal ultrasonography and from intraoperative findings. Final confirmatory diagnosis was made after histopathological report.

Those cases having complicated appendicitis involving appendicular mass, gangrene, perforation and abscess, comorbid cases like diabetes mellitus, immunocompromised status, those received antibiotics within 48 hours prior to surgery and negative histopathological report for acute appendicitis were excluded from the study.

All patients who fulfilled inclusion criteria were operated in the emergency theatre by different experienced surgeons. All patients received preoperative single dose and postoperative two doses of antibiotics (ceftriaxone and metronidazole) within 24 hours. Patients skin antisepsis and scrub was done with $10 \%$ povidone-iodine solution and operated with aseptic technique. Lanz skin incision was made to most of the patients. Fascial layer closed with polyglactin suture and skin closed with staples in all cases. Sterile dressing was kept for 48 hours and then left open. The wound was assessed after 48 hours and followed-up in outpatient basis till $7^{\text {th }}$ postoperative day. Wound infection was graded using the Southampton scoring system. ${ }^{5}$

\begin{tabular}{|l|l|}
\hline Grade & Wound appearance \\
\hline 0 & Normal healing \\
\hline 1 & Normal healing with mild bruising \\
\hline 2 & Erythema \\
\hline 3 & Clear discharge \\
\hline 4 & Purulent discharge \\
\hline 5 & Deep wound infection \\
\hline
\end{tabular}

Wound was considered as normal for grade 0,1 and 2. Minimal wound infection for grade 3 and major for grade 4 and 5 . Skin staples were removed on $7^{\text {th }}$ postoperative day. The collected data was recorded and analyzed using SPSS version 16.

\section{RESULTS}

A total of 100 patients, 57 (57\%) male and 43 (43\%) female were included in the study. The age ranged from 3-65 years with 27 (27\%) in age group of 3-15 years, 59 (59\%) in age group 16-39 years and 14 $(14 \%)$ in age group $\geq 40$ years. All patients underwent appendectomy and $83 \%$ appendectomies were carried out within $31-60$ minutes, $14 \%$ within 30 minutes and $3 \%$ required more than 60 minutes of operating time. All patients received single dose of antibiotics (ceftriaxone and metronidazole) during induction of anesthesia and two more doses of same antibiotics within 24 hours postoperatively. After 24 hours, 94 (94\%) patients were not require further course of antibiotics but 6(6\%) required oral antibiotics in following postoperative days due to SSIs (Table 1). Mean hospital stay was 2.3 days.

Table 1: Timing of antibiotics after 24 hours postoperative day $(n=100)$

\begin{tabular}{|l|l|}
\hline Antibiotics & Frequency (\%) \\
\hline Received & 6 \\
\hline Not received & 94 \\
\hline Total & 100 \\
\hline
\end{tabular}

In the postoperative period the surgical wounds were examined and SSIs graded using the Southampton scoring system. On $2^{\text {nd }}$ postoperative day, normal wound healing was noted in 56(56\%) male, 42(42\%) female and minimal wound infection was noted in $1(1 \%)$ of each sex which resolved spontaneously without further course of antibiotics and hospital stay $(p=0.840)$ (Table 2$)$. 
Table 2: Wound infection on $2^{\text {nd }}$ postoperative day with sex $(n=100, p=0.840)$

\begin{tabular}{|l|l|l|l|}
\hline Sex & $\begin{array}{l}\text { Normal wound } \\
\text { healing }\end{array}$ & Minimal infection & Total \\
\hline Male & 56 & 1 & 57 \\
\hline Female & 42 & 1 & 43 \\
\hline Total & 98 & 2 & 100 \\
\hline
\end{tabular}

On $3^{\text {rd }}$ postoperative day, normal wound healing was noted in 55 (55\%) male, 39(39\%) female and minimal wound infection was noted in $2(2 \%)$ male and $4(4 \%)$ female which required further course of oral antibiotics but not required further hospital stay. Infection was resolved after regular dressing with normal saline $(p=0.539)$ (Table 4). No major wound infection was noted up to $7^{\text {th }}$ postoperative day follow up.

Table 3: Wound infection on $2^{\text {nd }}$ postoperative day with age group $(n=100, p=0.700)$

\begin{tabular}{|l|l|l|l|}
\hline Age group & $\begin{array}{l}\text { Normal wound } \\
\text { healing }\end{array}$ & $\begin{array}{l}\text { Minimal } \\
\text { infection }\end{array}$ & Total \\
\hline $3-15$ years & 26 & 1 & 27 \\
\hline $\begin{array}{l}16-39 \\
\text { years }\end{array}$ & 58 & 1 & 59 \\
\hline $\begin{array}{l}40 \quad \text { and } \\
\text { above years }\end{array}$ & 14 & 0 & 14 \\
\hline Total & 98 & 2 & 100 \\
\hline
\end{tabular}

Minimal wound infection was noted more in 16-39 years age group on $2^{\text {nd }}$ and $3^{\text {rd }}$ postoperative day which was statistically not significant $(p=0.330)$ (Table 3 and 4).

Table 4: Wound infection on $3^{\text {rd }}$ postoperative day with sex and age group $(n=100, p=0.539)$

\begin{tabular}{|l|l|l|l|}
\hline Sex & $\begin{array}{l}\text { Normal wound } \\
\text { healing }\end{array}$ & $\begin{array}{l}\text { Min imal } \\
\text { infection }\end{array}$ & Total \\
\hline Male & 55 & 2 & 57 \\
\hline Female & 39 & 4 & 43 \\
\hline Total & 94 & 6 & 100 \\
\hline Age group & \multicolumn{5}{|l}{} \\
\hline 3-15 years & 26 & 1 & 27 \\
\hline $\begin{array}{l}\text { 16-39 years } \\
\text { 40 and } \\
\text { above years }\end{array}$ & 12 & 3 & 59 \\
\hline Total & 94 & 2 & 14 \\
\hline
\end{tabular}

The incidence and grade of wound infection was found statistically not significant $(p>0.05)$ using Chi square test.

\section{DISCUSSION}

Antibiotics prophylaxis is common in surgical practice but inappropriate use of antibiotics occurs in $25-50 \%$ of general elective surgery. ${ }^{6} \mathrm{~A}$ Cochrane systematic review found that antibiotic use in patients having uncomplicated appendicitis was superior to placebo in reducing the rates of postoperative complications but concluded that no recommendations can be made regarding the antibiotics use but at the same time advised to continue antibiotic regime in severe form of appendicitis. ${ }^{7}$

The choice and optimum duration of use of antibiotics varies widely in different centers and even among the different surgical units attached to the same institute. There is a major controversy on optimum duration of use of antibiotics in case of acute NPA and many studies have shown that the single or perioperative three doses of appropriate antibiotic is as effective as multiple postoperative doses in preventing wound infection following appendectomy. ${ }^{8}$

A cohort study conducted by Saadeldin Al et al had shown the incidence of wound infection (12.2\%) and mostly minimal infection $(7.45 \%)$ on perioperative use of antibiotics $(p>0.05) .{ }^{9}$

A randomized clinical trial by Sheik Abdullah et al concluded that single dose and two doses of antibiotics postoperatively was equally effective and no more postoperative dose is required to prevent wound infection in acute NPA $(p=0.986) .{ }^{10}$

A study by Muhammed SR et al had shown that perioperative use of antibiotics was adequate to prevent wound infection rather than use of multiple doses in postoperative days. ${ }^{11}$

In our study, we have used a more objective method to assess the progress of the surgical wounds by correlating with the Southampton scoring system. There was no significant difference in incidence and grade of wound infection following three doses of perioperative antibiotics in any age group, sex and operating time.

Many studies have highlighted the effects of im- 
proper choice and prolonged use of antibiotics on the increased risk of antibiotic resistance on common pathogens. ${ }^{12}$ Coakley et al have proven that postoperative prolonged antibiotic treatment for acute NPA did not reduce infectious complications but significantly increased the rate of adverse effects like Clostridium difficile infection, diarrhea, hospital stay and overall treatment cost. ${ }^{13}$

From our study, a possible benefit that can be derived is that the incidence of SSIs is not significant by using only three doses of antibiotics in perioperative period in acute NPA, so there is no benefit from prolonged use of further doses of antibiotics.

\section{CONCLUSION}

Three doses of perioperative antibiotics in acute NPA after appendectomy is adequate in preventing postoperative wound infection, in any age, sex and within usual operating time. It can be recommended that there is no additional benefit by continuing further doses of antibiotics in preventing wound infections. So, for surgeons it is essential to update their routine practice of antibiotic use according to the standard guidelines and evidence based medicine rather than irrational use of antibiotics.

\section{REFERENCES}

1. Busuttil RW, Davidson RK, Fine M, Tompkins RK. Effect of prophylactic antibiotics in acute nonperforated appendicitis. Am Surg1981;194:502-8.

2. Townsend Jr CM, Beauchamp RD, Evers BM, Mattox KL. Sabiston textbook of surgery: Elsevier Health Sciences; 2012.

3. Hussain MI, Alam MK, Al-Qahatani HH, Al-Akeely $\mathrm{MH}$. Role of postoperative antibiotics after appendectomy in non-perforated appendicitis. J Coll Physicians Surg Pak 2012;22:756-9.

4. Fraser JD, Aguayo P, Leys CM, Keckler SJ, Newland JG, Sharp SW, et al. A complete course of intravenous antibiotics vs. a combination of intravenous and oral antibiotics for perforated appendicitis in children: a prospective randomized trial. PediatrSurg 2010;45:1198-202.

5. Bailey SI, Karran SE, Toyn K, et al. Community surveillance of complications after hernia surgery. Brit Med J 1992;304:469-71.

6. Gyssens IC, Geerligs IE, Nannini-Bergman MG, Knape JT, HeksterYA, van der Meer JW. Optimizing the timing of antimicrobial prophylaxis in surgery: an intervention study. J AntimicrobChemother 1996;38:301-8.

7. Andersen BR, Kallehave $\mathrm{FL}$, Andersen $\mathrm{HK}$. Antibiotics versus placebo for prevention of postoperative infection after appendicectomy. Cochrane Database Syst Rev 2005; 3:CD001439.

8. Le D, Rusin W, Hill B, Langell J. Post-operative antibiotic use in nonperforated appendicitis. Am J Surg 2009;198:748-52.

9. SaadeldinAl,Aamir AH, AbuobiedaOS,et al. Timing and duration of antibiotic usage in appendectomies and its relation with surgical site infection. Open science journal of clinical medicine 2014;2(1):19-23.

10. Sheik A, Rajan V, Kannan R, et al. Randomized clinical trial of single versus three doses of cefazolin as prophylaxis for non-perforated acute appendicitis. Int J Cur Res Rev 2012;4(23):12430.

11. Muhammad SR, Mah MK, Attaullah K, et al. Evaluation of postoperative antibiotics after non perforated appendectomy. JPMA 2015;65:815-7.

12. Paterson DL, Rossi F, Baquero F, Hsueh PR, Woods GL, SatishchandranV, et al. In vitro susceptibilities of aerobic and facultative Gramnegative bacilli isolated from patients with intraabdominal infections worldwide: the 2003 Study for Monitoring Antimicrobial Resistance Trends (SMART). J AntimicrobChemother 2005;55:96573.

13. Coakley BA, Sussman ES, Wolfson TS, Bhagavath AS, Choi JJ, Ranasinghe NE, et al. Postoperative antibiotics correlate with worse outcomes after appendectomy for nonperforated appendicitis. J Am CollSurg 2011;213:778-83. 